\section{Anaesthesia for cervical laminectomy in a patient with total anomalous pulmonary venous connection}

Shubha N. Mohite MD (ANAES),

V.M. Divekar BSc MBBS DA MD
A 45-yr-old male patient, having total anomalous pulmonary venous connection (TAPVC) underwent cervical laminectomy under general anaesthesia without complication. The case was diagnosed preoperatively by angiocardiography. An uncomplicated patient of TAPVC can undergo non-cardiac surgery with due precaution against air-embolism and hypoxaemia.

Un homme de 45 ans porteur d'un retour pulmonaire veineux anormal total subit une laminectomie cervicale sous anesthésie générale sans complications. Le diagnostic avait été porté par angiocardiographie avant l'opération. Il est possible de soumettre ce type de malade à une chirurgie non cardiaque si on prévient les embolie gazeuses et l'hypoxémie.

Total anomalous pulmonary venous connection (TAPVC) is a condition in which all venous blood from both lungs enters the right atrium directly or through one of its tributory veins (Figure).

The incidence of TAPVC is $2 \%$ of 800 autopsied $^{1}$ cases of congenital heart disease in one series, with a marked preponderance amongs males. Only a few patients can survive to adulthood. Seventy-five to eighty percent of the patients are dead by one year of age.

Besides lack of excessive pulmonary vascular resistance, ${ }^{2}$ survival in TAPVC appears to be dependent primarily on three factors:

\section{Key words}

HEART: congenital defects, anomalous pulmonary venous connections;

LUNG: pulmonary veins;

SURGERY: orthopaedic.

From the Department of Anaesthesiology, Topiwala National Medical College, Bombay, India.

Address correspondence to: Dr. (Mrs.) S.N. Mohite, Department of Anaesthesiology, Topiwala National Medical College, Bombay Central, Bombay 400 018, India.

Accepted for publication March 3, 1993.
1 the size of the defect in the atrial septum;

2 the length of the anomalous pulmonary vein(s);

3 the degree of obstruction to flow in the anomalous pulmonary vein(s).

In these patients dyspnoea is the first complaint, ${ }^{3}$ followed by intermittent cyanosis and cardiac failure being the commonest cause of death. The ECG shows right axis deviation with tall peaked $\mathbf{P}$ waves characteristic of right atrial enlargement, the pre-cordial leads show evidence of right ventricular hypertrophy. The $x$-ray shows prominent pulmonary plethora, dilated pulmonary trunk, enlarged right atrium and right ventricle.

\section{Case report}

A 45-yr-old man, of very small stature, weighing $38 \mathrm{~kg}$ was admitted after falling from a bullock cart eight months previously. He had been unconscious for four days at that time. He then developed tingling and numbness in the upper and lower extremities. On further enquiry he complained of palpitation and dyspnoea after exertion for the past two to three years. There was no giddiness, syncope or foot oedema nor was there any history of major illness.

On neurological examination there was weakness of the muscles of both hands and atrophy of the right shoulder girdle. The temperature and pressure sensations were reduced below $\mathrm{C}_{3}$ level. The reflexes were more brisk on left side than on the right side and the gait was spastic. Myelography of the cervical spine showed bilateral compression of the roots at $\mathrm{C}_{5-6-7}$ due to disc protrusion and cervical canal stenosis.

On examination, the heart rate was regular, $72 \cdot \mathrm{min}^{-1}$. $\mathrm{BP}$ was $124 / 80 \mathrm{mmHg}$ and jugular pulsations were seen. There was grade III clubbing and cyanosis.

Cardiovascular system: Cardiomegaly was present. Ausculation revealed a mid-diastolic murmur in the mitral area due perhaps to increased flow across the mitral valve. Loud $\mathrm{S}_{1}$ chest $x$-ray, PA view showed cardiothoracic ratio of $55 \%$, increased vascularity and dilated superior vena cava. The ECG showed sinus rhythm, 


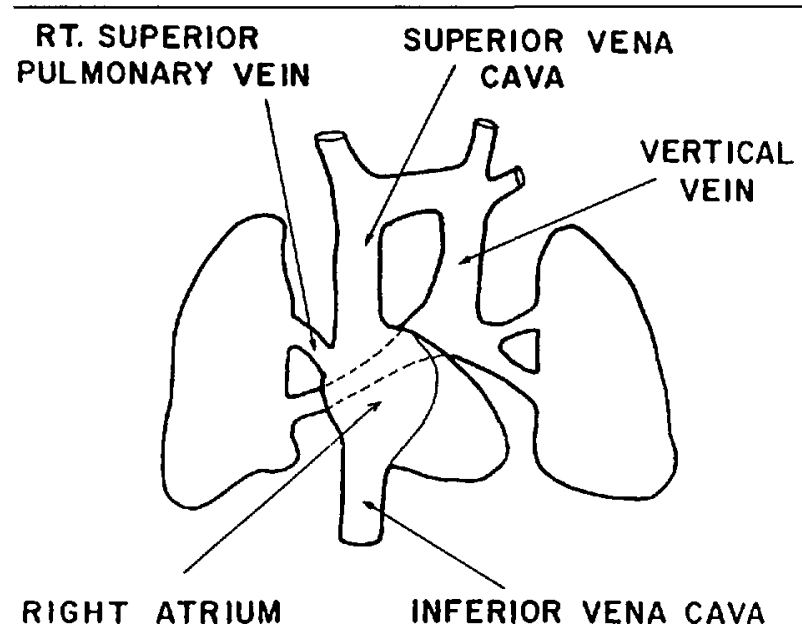

FIGURE

right axis deviation, ST flattening in II, III and VF with biphasic $T$ waves and tall $R$ waves in $V_{1-2}$ with inverted $T$ waves, indicating right ventricular enlargement.

Angiocardiography showed evidence of congenital heart disease. There was total anomalous pulmonary venous connection of the supradiaphragmatic mixed type. The right superior pulmonary vein drained into the right atrium. The other pulmonary veins formed a left vertical vein which entered the left innominate vein. There was no stenosis of the left vertical vein and innominate vein. There was a large non-restrictive ASD, a normally functioning left ventricle and mild pulmonary hypertension, i.e., $45 / 12 \mathrm{mmHg}$ and mean pressure of $25 \mathrm{mmHg}$. Oxymetry showed the following values of oxygen saturation in various chambers, right ventricle $89 \%$, right atrium $89 \%$, inferior vena cava $72 \%$, right innominate vein $89 \%$, superior vena cava $92 \%$, left atrium $89 \%$, and left ventricle $89 \%$. Almost equal saturation in the right and left heart samples is characteristically seen in TAPVC.

The patient was booked for surgery of cervical spine. The blood gas analyses just before the induction of anaesthesia showed $\mathrm{PaO}_{2} 50 \mathrm{mmHg}, \mathrm{PaCO}_{2} 34 \mathrm{mmHg}, \mathrm{pH}$ 7.44. The patient received premedication with atropine $0.6 \mathrm{mg} \mathrm{im}$, and buprenorphine $0.15 \mathrm{mg}, 30 \mathrm{~min}$ before surgery. Induction of anaesthesia was with thiopentone $175 \mathrm{mg} \dot{N}$, followed by succinyl choline $70 \mathrm{mg}$. Due precaution was taken for meticulous removal of air from the syringes and $i v$ lines while injecting drugs, as the hazard of systemic air embolism is very high. The heart was monitored by precordial stethoscope. After spraying the cords with lignocaine $4 \%$, the trachea was intubated with a flexometallic tube. Anaesthesia was maintained with $\mathrm{O}_{2}\left(\mathrm{FlO}_{2}\right.$ of 0.5$)$ and $\mathrm{N}_{2} \mathrm{O}$ and muscle relaxation with pancuronium $9 \mathrm{mg} i \mathrm{i}$. After induction the BP decreased from $100 \mathrm{mmHg}$ to $70 \mathrm{mmHg}$ but after $30 \mathrm{~min}$ the systolic pressure returned spontaneously to 100 $\mathrm{mmHg}$ and the patient was placed in the sitting position for surgery. The further course of anaesthesia and surgery was uneventful. The patient received $5 \%$ glucose 1500 $\mathrm{ml}$ with Ringer's lactate and one unit of blood. He was given $i v$ hydrocortisone $100 \mathrm{mg}$ and dexamethasone 4 mg during the course of anaesthesia. The blood gas values during operation were as follows: $\mathrm{pH} 7.465, \mathrm{PaO}_{2}$ $171.2 \mathrm{mmHg}, \mathrm{PaCO}_{2} 292.2 \mathrm{mmHg}$.

Reversal of neuromuscular blockade was with atropine $1.2 \mathrm{mg}$ and neostigmine $2.5 \mathrm{mg}$ and the trachea was extubated. The postoperative variables were BP $110 / 80$ $\mathrm{mmHg}$, heart rate $100 \cdot \mathrm{min}^{-1}$, respiratory rate $24 \cdot \mathrm{min}^{-1}$ and he responded to verbal commands. The patient was kept under observation in the recovery room for $24 \mathrm{hr}$ and the recovery was uncomplicated.

One hour after operation with $\mathrm{FiO}_{2}$ of 0.4 the blood gas analyses showed $\mathrm{PaO}_{2} 107.6 \mathrm{mmHg}, \mathrm{PaCO}_{2} 24.1$ $\mathrm{mmHg}, \mathrm{pH} 7.487$.

Twenty-four hours after operation $\left(\mathrm{FIO}_{2}-0.21\right) \mathrm{PaO}_{2}$ was $69.6 \mathrm{mmHg}$ with $\mathrm{PaCO}_{2}$ of $29.2 \mathrm{mmHg}$ and $\mathrm{pH}$ of 7.465 .

\section{Discussion}

The majority of patients with this anomaly who present ${ }^{4}$ for elective non-cardiac surgery will have undergone a corrective procedure. Since adequate surgical survival has occurred only in recent years, no long-term observations are yet available. In patients with pulmonary vascular disease at the time of corrective surgery, progression of the pulmonary arteriolar obstruction may occur, leading to secondary pulmonary venous and arterial hypertension with a clinical picture similar to that seen in patients with mitral stenosis.

Our patient appears to have survived for so long $^{3}$ because he had a large non-restrictive ASD, without any obstruction to pulmonary venous flow and a short course of the connecting anomalous vein. This patient has mild pulmonary hypertension, so he requires a corrective surgery, ${ }^{5}$ which includes closure of communicating channel and anastomosis of pulmonary venous channel to the left atrium. If corrective surgery is not performed, the patient will develop moderate and then severe pulmonary hypertension leading to cyanosis, chronic and recurrent cardiac failure and death.

Patients who have not undergone any corrective surgery ${ }^{4}$ and present with a widely patent interatrial connection without venous obstruction, a moderate increase in pulmonary arteriolar resistance with unrestricted pulmonary blood flow, will present with few clinical symptoms. They remain acyanotic for many years of life. The increased incidence of cyanosis suggests increasing pulmonary vascular resistance. In these patients hypoxia, hy- 
percarbia or a fall in systemic vascular resistance should be strictly avoided as it will further increase the pulmonary vascular resistance. Due to presence of intracardiac shunt, special care should be taken to prevent air embolism, during $i v$ infusions and drug injections. Oesophageal or precordial stethoscope, electrocardiogram, monitoring of arterial blood pressure and central venous pressure are the primary measures of monitoring the presence of air embolism. ${ }^{6}$ Precordial Doppler ultrasound monitor is the most sensitive device used for this purpose. If the Doppler monitor indicates air in the vascular system, nitrous oxide should be discontinued and other appropriate measures adopted. Prophylactic antibiotic cover should be given to these patients to prevent subacute bacterial endocarditis.

In conclusion, these uncomplicated cases of TAPVC can be managed safely if due precaution is taken against hypoxia, hypotension, and air embolism. The doses of anaesthetic agents may be chosen to allow rapid awakening and immediate resumption of spontaneous respiration postoperatively.

\section{Acknowledgement}

We are grateful to Dr. (Mrs.) K.D. Nihalani, Dean, B.Y.L. Nair Charitable Hospital and T.N. Medical College, Bombay, India, for permitting us to publish this article.

\section{References}

1 Lucas $R V$. Anomalous venous connections, pulmonary and systemic. In: Arthur J. Moss et al. (Eds.). Heart Diseases in Infants, Children and Adolescents, 2nd Ed. Baltimore: Williams \& Wilkins. 1977; 444-53.

2 McManus BM, Luetzeler J, Roberts WC. Total anomalous pulmonary connection: survival for 62 years without surgical intervention. Am Heart J. 1982; 103: 298-301.

3 Perloff $J K$. The Clinical Recognition of Congenital Heart Disease, Philadelphia: WB Saunders. 1970; 258-70.

4 Hollingerer IB. Diseases of the cardiovascular system. In: Katz J, Steward DJ (Eds.). Anaesthesia and Uncommon Pediatric Diseases, Philadelphia: WB Saunders. 1987; 132-3.

5 Gothard JWW, Branthwaite MA. Congenital heart disease and the principles of paediatric cardiac surgery. In: Gothard JWW (Ed.). Anaesthesia for Cardiac Surgery and Allied Procedures, 3rd Ed., London: Blackwell. 1987; 263-4.

6 Rubin RC, Frost $E A M$. Posterior cranial fossa surgery. In: Frost EAM (Ed.). Clinical Anaesthesia in Neurosurgery, Boston: Butterworth Publishers. 1984; 165-8. 